\title{
Residência Multiprofissional em Oncologia e Serviço Social: Tendências e Desafios em Tempos de Pandemia da Covid-19
}

doi: https://doi.org/10.32635/2176-9745.RBC.2020v66nTemaAtual.1131

\author{
Multiprofessional Residency in Oncology and Social Work: Trends and Challenges in the COVID-19 Pandemic Period \\ Residencia Multiprofesional en Oncología y Trabajo Social: Tendencias y Desafíos en Tiempos de Pandemia de Covid-19
}

Gabriela Lopes Cardoso'; Licya Viviane de Sousa Costa²

\section{INTRODUÇÃO}

O ano é 2020. Está em curso uma pandemia causada pela síndrome respiratória aguda grave do coronavírus 2 (severe acute respiratory syndrome coronavirus 2 - Sars-CoV-2), originando a doença pelo coronavírus 2019 (coronavirus disease 2019 - Covid-19) ${ }^{1}$, que atravessou fronteiras, disseminando-se em níveis diferentes nos sujeitos do Brasil e do mundo. O indivíduo atendido pelo Serviço Social de uma instituição de saúde especializada em tratamento oncológico possui câncer (um conjunto de mais de 100 doenças), o que já o coloca em vulnerabilidade em relaçáo à sua saúde, a depender do grau de sua neoplasia, quando se considera a gravidade de infecção pela Covid-19.

De acordo com o mapeamento da Associação Brasileira de Ensino e Pesquisa em Serviço Social (ABEPSS) de $2018^{2}$, existem 23 instituiçóes de saúde que possuem como modalidade o Programa de Residência Multiprofissional em Oncologia, como consta na Lei n. ${ }^{\circ} 11.129$, de 30 de junho de $2005^{3}$, que institui a Residência em Área Profissional de Saúde e cria a Comissão Nacional de Residência Multiprofissional em Saúde (CNRMS). O programa constitui o ensino de pós-graduação lato sensu, atendendo a diversas profissóes da área da saúde, como o Serviço Social, que está inserido na Portaria Interministerial MEC/MS n. ${ }^{\circ} 1.077$, de 12 de novembro de $2009^{4}$ e dispóe sobre a Residência Multiprofissional em Saúde e a Residência em Área Profissional da Saúde. Além disso, institui o Programa Nacional de Bolsas para Residências Multiprofissionais e em Área Profissional da Saúde e a CNRMS. As residentes de Serviço Social escreveram este artigo a partir de uma experiência em campo em um hospital oncológico de referência no Brasil com atendimentos aos usuários e relaçóes com a equipe multiprofissional.
Com isso, possui como eixo norteador a integração "ensino-serviço-comunidade"; ou seja, os assistentes sociais residentes, assim como as outras categorias como Psicologia, Enfermagem, Farmácia etc., estão no processo pedagógico da especialização no campo prático da sua atuação, a partir dos atendimentos aos usuários do Sistema Único de Saúde (SUS) e na sua relação com a equipe multiprofissional.

De acordo com Bravo e Matos ${ }^{5}$, desde a década de 1980, com os movimentos de redemocratização no Brasil, o Serviço Social corrobora e está alinhado com os princípios e diretrizes da Lei no. 8.080, de 19 de setembro de $1990^{6}$. De fato, a renovação e a maturação da profissão se dão nessa época junto com o Movimento de Reforma Sanitária para a consolidação do SUS na Constituição Federal de $1988^{7}$.

Dessa forma, como se vê no Código de Ética de 1993 do Conselho Federal de Serviço Social ${ }^{8}$, há princípios que estão de acordo com os do SUS, como a democratização e a universalização do acesso aos serviços públicos; a equidade e a justiça social nos atendimentos aos usuários sem discriminaçáo de raça, gênero e classe; e a integralidade pensando no cuidado integral organizado em rede aos sujeitos que usufruem dos serviços na alta, média e baixa complexidades na referência e contrarreferência do sistema.

Portanto, em virtude dessa convergência de projetos políticos, as assistentes sociais residentes contribuem em conjunto com as assistentes sociais da instituição na defesa do SUS e do acesso à informação, como os direitos sociais dos pacientes e suas famílias. Assim, principalmente em tempos em que os governos decretam calamidade pública por causa de uma pandemia, as demandas e a necessidade de orientações de forma clara, objetiva e resolutiva aumentam exponencialmente.

Assim sendo, esse usuário supracitado, que nos acessa, pertence - em sua maioria - à classe trabalhadora, a

${ }^{1}$ Assistente Social da Universidade Federal do Rio de Janeiro (UFRJ). Rio de Janeiro (RJ), Brasil. Orcid iD: https://orcid.org/0000-0003-4016-9196 ${ }^{2}$ Assistente Social da UFRJ. Especialista em Saúde Pública e Direitos Humanos pela Fundação Oswaldo Cruz (Fiocruz). Rio de Janeiro (RJ), Brasil. Orcid iD: https:// orcid.org/0000-0002-0903-0316

Endereço para correspondência: Gabriela Lopes Cardoso. Rua Flamínia, 450, apto. 903 - Penha Circular. Rio de Janeiro (RJ), Brasil. CEP 21221-240. E-mail: gabilpcardoso@gmail.com 
qual tem sido lesada e atingida em diversas frentes de trabalho durante essa pandemia. Em razão da situação de calamidade pública e recomendaçóes sanitárias ${ }^{9}$, muitos locais que geravam emprego tiveram que fechar suas portas, ocasionando uma forte onda de desemprego, redução de salários e suspensôes de contrato. Além de impactar demasiadamente os trabalhadores informais, os quais não terão acesso a diversos direitos trabalhistas e previdenciários ${ }^{10}$. A única ação protetiva acordada pelo Governo Federal foi o auxílio emergencial, que consta na Lei $\mathrm{n}^{\circ} 13.982$, de 2 de abril de $2020^{11}$, e estabelece medidas de enfrentamento da emergência de saúde pública causada pela Covid-19.

Esses trabalhadores e desempregados são os que mais têm buscado o Serviço Social na intençấo da nossa interferência, para que se consigam fontes e contato com setores da rede socioassistencial, a fim de assegurar o mínimo de subsídio para atender às suas necessidades imediatas, a exemplo da alimentação. Dessa forma, no contexto de atendimentos aos pacientes do hospital oncológico, conta-se com a parceria do terceiro setor - instituição responsável pela promoção de açóes voluntárias aos pacientes - que, a partir de doaçóes, possibilita o acesso ao benefício da bolsa de alimentos, assim como o auxílio para o transporte (quando esgotadas as tentativas das políticas públicas na área do transporte), objetivando a adesão ao tratamento.

\section{DESENVOLVIMENTO}

\section{O SERVIÇO SOCIAL NA RESIDÊNCIA MULTIPROFISSIONAL EM ONCOLOGIA NO CONTEXTO DA PANDEMIA DE COVID-19: ALGUNS APONTAMENTOS}

Este artigo tem como norte a abordagem sobre as mudanças de fluxo no funcionamento do Serviço Social de um hospital especializado em oncologia, sendo dividido em clínicas de origem como: Pediatria, Cabeça e Pescoço, Abdômen, Urologia, Oncologia, Hematologia, Tórax etc. Contudo, em tempos de pandemia, foi modificada e flexibilizada a atuaçáo das assistentes sociais com o objetivo de atender a todas as demandas dos pacientes e suas famílias - inclusive as mais urgentes - que ingressavam no hospital. Com isso, até o momento, foi decidido, pela chefia do Serviço Social, que as profissionais e as residentes atuariam em escalas para diminuir a circulação de pessoas na instituição e, dessa forma, trabalhariam no ambulatório e nas enfermarias (COVID FREE) - livre de contaminação de coronavírus - sem diversificar a clínica. Assim sendo, o setor passou a atender de forma continuada, espontânea e sem agendamento por parte dos usuários, a fim de evitar o seu trajeto em transportes públicos.

Nesse contexto pandêmico, tem-se enfrentado dificuldades no acesso a diversos serviços, por conta do fechamento de setores e diminuição de corpo técnico e profissional. Dessa maneira, uma das maiores dificuldades como assistentes sociais tem sido buscar alternativas e fontes para que os pacientes náo desistam e abandonem o tratamento de câncer. $O$ transporte público, por exemplo, é um dos serviços mais afetados pela pandemia, constituindo um grande impasse no deslocamento da residência ao hospital.

Outros serviços e programas padecem do mesmo impacto, especialmente os postos de realização do vale-social e clínicas da família que realizavam o cadastramento do Riocard Especial e estavam, até o momento, fechados e sem indicativo de retorno de funcionamento. $\mathrm{Ou}$ seja, muitos pacientes e seus acompanhantes tinham que escolher entre comprar sua alimentação ou custear suas passagens de ida e volta ao seu local de tratamento especializado em oncologia. Ademais, usuários residentes fora do município do Rio de Janeiro têm dificuldades para o acesso ao Tratamento Fora de Domicílio (TFD) quando encaminhados para esse instrumento legal instituído pela Portaria MS/SAS n. ${ }^{\circ}$ 55, de 24 de fevereiro de $1999^{12}$.

Dessa maneira, criaram-se estratégias como: averiguar telefones e correios eletrônicos das Secretarias de Saúde de cada município possíveis para contato, verificar quais as clínicas da família estavam em funcionamento para a realização do Riocard Especial, obter conhecimento acerca da possibilidade dos usuários do hospital oncológico não necessitarem apresentar o vale-social para a realizaçáo de tratamento nos trens, metrôs e ônibus intermunicipais, entre outras questôes que repercutem na continuidade e adesão ao tratamento.

Também se destaca aqui a enorme contribuição para o nosso trabalho assistencial na instituição filantrópica e a parceria do hospital no favorecimento da continuidade ao tratamento oncológico a partir da ajuda com um auxílio-transporte, quando o Estado não oferece mais nenhuma alternativa para garantir a promoção e o controle do câncer em tempos de pandemia. Junto a isso, faz parte do nosso trabalho institucional avaliar a necessidade de encaminhamento para a bolsa de alimentos como doação dessa mesma instituição. Compreende-se, como equipe de Serviço Social e profissionais de saúde do SUS, o conceito ampliado de saúde que é resultante de diversos determinantes sociais (alimentação, educação, meio ambiente, transporte, renda, trabalho etc.) como consta nos Anais da $8^{a}$ Conferência Nacional de Saúde (CNS) de $1986^{13}$ e no art. $3^{\circ}$ da Lei n. ${ }^{\circ} 8.080^{6}$, para a contribuição do controle e tratamento oncológico.

Ao analisar o contexto de pandemia dentro desse nosso sistema societário, que possui como norte a ideologia neoliberal com o enxugamento de políticas públicas pelo Estado e a ampliação dos domínios do capital, verifica-se 
que, em tempos de Covid-19, esses termos se agudizam. Agudizam como? Ao fornecer o auxílio emergencial de forma mecânica e focalizada, com duros critérios de elegibilidade, enorme burocracia e tecnologização para acesso, fazendo com que a massa de explorados de fato não conseguisse ter plenitude para obtenção de tal benefício. Benefício este que somente era obtido por meio de um aplicativo criado pelo Governo Federal, cabendo ao usuário ter um aparelho celular e Internet, além da compreensão do funcionamento desse aplicativo.

Para além disso, os usuários se depararam com inúmeras burocracias que os impediram na concessão do auxílio como: irregularidade no Cadastro de Pessoa Física, estar com vínculo em aberto na carteira de trabalho, problemas técnicos no aplicativo, não ser contribuinte individual no Instituto Nacional de Seguridade Social, necessidade de estar inscrito no Cadastro Único (CadÚnico) etc. Assim, a equipe de assistentes sociais do hospital oncológico, em conjunto com as residentes de Serviço Social, buscou contato com a Defensoria Pública do Rio de Janeiro (DPRJ) na tentativa de colaboração na resolutividade dos auxílios emergenciais que estavam "em análise" ou tinham sido negados, dos pacientes e suas famílias. É válido ressaltar que muitos desses usuários estavam sem renda e sobrevivendo a partir de doaçóes e ajuda de terceiros, quando na verdade deveriam estar recebendo esse direito sancionado pelo Governo Brasileiro.

\section{CONCLUSÃO}

A importância do Serviço Social está em ser ponte dialógica com os diversos aparelhos protetivos e assistenciais ao nosso usuário, o qual já se encontra em um processo complexo de adoecimento, cuja realidade social, psicológica, econômica e toda série de determinantes sociais se modificam, dado o risco de morte que essa doença provoca. Ademais, o câncer se apresenta para muitos pacientes em um contexto de pandemia, gerando um impacto ainda maior em suas vidas.

Para os residentes do Serviço Social do hospital oncológico de referência do Brasil, ainda em processo de aprendizado e especialização sobre as Políticas e Direitos Sociais da Seguridade Social, Legislaçôes específicas da Política Nacional de Câncer e sua aplicabilidade e compreensão do fluxo institucional e de atendimento aos usuários, há a necessidade de atualização constantemente nesse momento. Inclusive acerca das informações, as quais, muitas vezes, são instáveis do ponto de vista de permanência e na sua concretude.

Assim, como profissionais da saúde, é preciso oferecer um serviço de qualidade para os usuários do hospital oncológico do SUS e contribuir para a afirmação de que o Estado deve prevenir, promover e proteger a saúde de forma coletiva e universal. Compreende-se, ainda, que vários serão os desafios, particularmente no que se refere à reabertura gradual dos setores e à necessária reorganização do nosso atendimento em articulação com os serviços e programas relativos ao tratamento oncológico.

\section{CONTRIBUIÇÕES}

Ambas as autoras contribuíram substancialmente em todas as etapas do artigo e aprovaram a versáo final a ser publicada.

\section{DECLARAÇÃO DE CONFLITO DE INTERESSES}

Nada a declarar.

\section{FONTES DE FINANCIAMENTO}

Não há.

\section{REFERÊNCIAS}

1. Organização Pan-Americana da Saúde (BR) [Internet]. Brasília, DF: OPAS; [data desconhecida]. Folha informativa COVID-19: escritório da OPAS e da OMS no Brasil; [atualizada 2020 set 18; acesso 2020 maio 28]. Disponível em: https://www.paho.org/bra/index. php?option $=$ com_content\&view $=$ article $\&$ id $=6101: \mathrm{cov}$ id19\&Itemid $=875$

2. Associação Brasileira de Ensino e Pesquisa em Serviço Social. Relatório da pesquisa mapeamento das residências em área profissional e Serviço Social [Internet]. Juiz de Fora, MG: UFJF; 2018 [acesso 2020 jun 01]. Disponível em: http://www.abepss.org.br/arquivos/anexos/relatorioabepss-residencia-201812031150396627330.pdf

3. Presidência da República (BR). Lei no 11.129 , de junho 30 de junho de 2005. Institui o Programa Nacional de Inclusão de Jovens - ProJovem; cria o Conselho Nacional da Juventude - CNJ e a Secretaria Nacional de Juventude; altera as Leis ${ }^{\circ}$ s 10.683 , de 28 de maio de 2003, e 10.429, de 24 de abril de 2002; e dá outras providências [Internet]. Diário Oficial da União. 2005 jul 1; Seção 1:1 [acesso 2020 jun 01]. Disponível em: http:// www.planalto.gov.br/ccivil_03/_Ato2004-2006/2005/ Lei/L11129.htm

4. Ministério da Educação (BR); Ministério da Saúde (BR). Portaria Interministerial MEC/MS $\mathrm{n}^{\circ}$ 1.077, de 12 de novembro de 2009. Dispóe sobre a Residência Multiprofissional em Saúde e a Residência em Área Profissional da Saúde, e institui o Programa Nacional de Bolsas para Residências Multiprofissionais e em Área Profissional da Saúde e a Comissão Nacional de Residência Multiprofissional 
em Saúde [Internet]. Diário Oficial da União. 2009 nov 13; Seção 1:7 [acesso 2020 maio 21]. Disponível em: http://portal.mec.gov.br/index.php?option=com_ docman\&view=download\&alias=15462-por -1077 12nov-2009\&Itemid $=30192$

5. Mota AE, Bravo MIS, Nogueira VMR, et al, organizadores. Serviço social e saúde: formação e trabalho profissional [Internet]. 2. ed. São Paulo: Cortez; 2007. Part. 2.3, Bravo MI, Matos MC. Projeto ético-político do serviço social e sua relação com a reforma sanitária: elementos para o debate [acesso 2020 jun 02]; p. 1-22. Disponível em: http://www.cressrn.org.br/files/arquivos/ ceJ472Fic4P2HK6fVV92.pdf

6. Presidência da República (BR). Lei no 8.080 , de 19 de setembro de 1990. Dispóe sobre as condiçóes para a promoção, proteção e recuperação da saúde, a organização e o funcionamento dos serviços correspondentes e dá outras providências [Internet]. Diário Oficial da União. 1990 set 20; Seção 1:1 [acesso 2020 maio 20]. Disponível em: http://www.planalto.gov.br/ccivil_03/leis/18080.htm

7. Presidência da República (BR). Constituiçẫo (1988). Constituição da República Federativa do Brasil [Internet]. Brasília, DF: Senado Federal; 1988. [acesso 2020 maio 20]. Disponível em: http://www.planalto.gov. br/ccivil_03/constituicao/constituicao.htm

8. Conselho Federal de Serviço Social (BR). Código de ética do/a assistente social: lei 8.662/93 de regulamentação da profissão [Internet]. $10 \mathrm{ed}$. rev. atual. Brasília, DF: CFESS; [2012] [acesso 2020 maio 20]. Disponível em: http://www.cfess.org.br/arquivos/ CEP_CFESS-SITE.pdf

9. UOL [Internet]. São Paulo: Universo Online; c1996 2020. Slattery G, Boadle A. Fantasma da fome cresce no Brasil com destruição da renda na pandemia; 2020 abr 04 [acesso 2020 maio 29]. Disponível em: https:// economia.uol.com.br/noticias/reuters/2020/04/21/ enfoque-fantasma-da-fome-cresce-no-brasil-comdestruicao-da-renda-na-pandemia.htm

10. Ministério da Saúde (BR). Recomendaçôes do Ministério da Saúde e da ANVISA para a operação Regresso [Internet]. Brasília, DF: Ministério da Saúde; 2020 [acesso 2020 maio 26]. Disponível em: https://portalarquivos2.saude.gov.br/ images/Recomenda\%C3\%A7\%C3\%B5es_do_ Minist\%C3\%A9rio_da_Sa\%C3\%BAde_e_da_ ANVISA_para_a_opera\%C3\%A7\%C3\%A3o_ Regresso.pdf

11. Presidência da República (BR). Lei no 13.982 , de 2 de abril de 2020. Altera a Lei no 8.742 , de 7 de dezembro de 1993, para dispor sobre parâmetros adicionais de caracterização da situação de vulnerabilidade social para fins de elegibilidade ao benefício de prestação continuada (BPC), e estabelece medidas excepcionais de proteçáo social a serem adotadas durante o período de enfrentamento da emergência de saúde pública de importância internacional decorrente do coronavírus (Covid-19) responsável pelo surto de 2019, a que se refere a Lei no 13.979, de 6 de fevereiro de 2020. Diário Oficial da União. 2020 abr 2; Seçáo 1:1 [acesso 2020 maio 22]. Disponível em: http://www.in.gov.br/en/web/ dou/-/lei-n-13.982-de-2-de-abril-de-2020-250915958

12. Ministério da Saúde (BR). Portaria MS/SAS no 55, de 24 de fevereiro de 1999. Dispóe sobre a rotina do Tratamento Fora de Domicílio no Sistema Único de Saúde - SUS, com inclusão dos procedimentos específicos na tabela de procedimentos do Sistema de Informaçóes Ambulatoriais do SIA/SUS e dá outras providências [Internet]. Diário Oficial da União. 1999 fev 26; Seção 1:116 [acesso 2020 maio 27]. Disponível em: https://bvsms.saude.gov.br/ bvs/saudelegis/sas/1999/prt0055_24_02_1999.html

13. Ministério da Saúde (BR). Anais da $8^{a}$ Conferência Nacional de Saúde [Internet]; 1986 mar 17-21; Ginásio Nilson Nelson, Brasília, DF. Brasília, DF: Centro de Documentação do Ministério da Saúde; 1987 [acesso 2020 jun 01]. Disponível em: http://www.ccs.saude.gov. $\mathrm{br} / \mathrm{cns} / \mathrm{pdfs} / 8$ conferencia/8conf_nac_anais.pdf

Recebido em 30/6/2020 Aprovado em 11/9/2020 